\title{
METHOD OF REMOVING WOODEN SPLINTERS FROM THE CORNEA*
}

BY

\section{J. MOSS}

\section{Birmingham United Hospitals and Birmingham Eye Hospital}

THIS case was thought to be worth recording as a search through the literature revealed no description of the method used. Only one reference was found dealing with the removal of wooden splinters from the cornea (Weber, 1949).

\section{Case Report}

The patient was a carpenter and first presented himself as an out-patient at Leamington Spa Hospital in February, 1956. He stated that while fitting a door frame, and hammering nails into it, he felt something go into his eye.

Examination.-A wooden splinter was present in the cornea and could be seen easily with the slit lamp. It was situated in the centre of the right cornea and its anterior end was about half way between the epithelium and endothelium. The posterior end projected into the anterior chamber and about two-thirds of the total length of the splinter was in the anterior chamber (Figure). The splinter was directed at the centre of the lens capsule $(\mathrm{A})$.

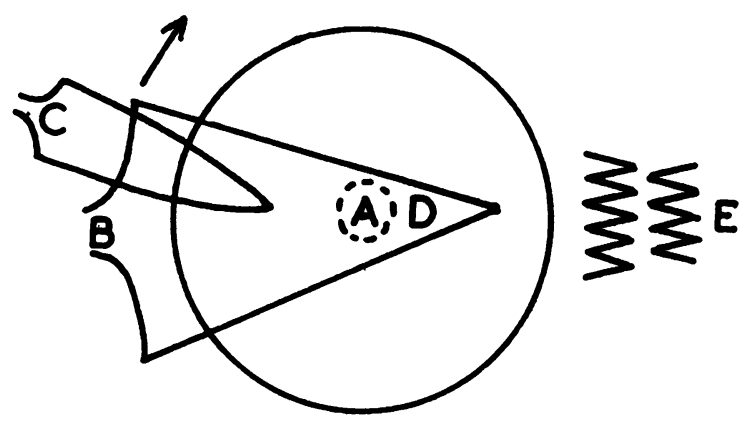

Figure.-Diagram of position of splinter and insertion of keratomes.
A. Perforating track with splinter.
B. Jaeger keratome.
C. Second keratome enlarging incision upwards in direction of arrow.
D. Outline of pupil.
E. Fixation point.

Treatment.-The eye was fairly quiet and it was decided to try conservative treatment for a time. Guttae atropine 1 per cent., guttae cortisone 1 per cent., and guttae penicillin were given, but whenever treatment was stopped the eye became injected. 
In May, 3 months later, the patient was referred to the Birmingham and Midland Eye Hospital. The fundus could be seen easily and there was no evidence of any damage to the lens. The visual acuity in the right eye was 6/12 unaided. An $x$-ray of the right orbit excluded a metallic foreign body. The consultant surgeons' opinions were sought, and it was thought that the foreign body should be removed.

An unsuccessful attempt was made to remove it on May 24, by endeavouring to lay bare the anterior end of the splinter and grasp it with forceps. This is essentially the method used by Weber (1949), with the difference that he used two von Graefe knives to grasp the splinter. In this case, however, the anterior end of the splinter was too deep.

Operation.-On May 28 miosis was achieved with guttae diisopropyl fluorophosphonate 0.2 per cent. and the next day an incision was made with a Jaeger keratome at 9 o'clock (B). This caused the pupil to dilate to a small extent. The keratome was therefore passed right across the anterior chamber to remain as a protection for the lens. A narrower keratome was then inserted into the wound $(C)$ and an enlargement made up to 11 o'clock. This allowed sufficient room for a pair of straight non-toothed iris forceps to be introduced into the anterior chamber in front of the Jaeger keratome. The splinter was grasped in these forceps and removed. Guttae atropine 1 per cent. and guttae chloramphenicol 0.5 per cent. were instilled, and the patient was returned to the ward with a pad and bandage.

Result.-The keratome incision healed well, but an opacity developed just central to it. This was due to the rather large extent of the incision, and cleared in a day or two. The perforating track also healed with no trouble. There were a few cells in the anterior chamber for a day or two, but these quickly disappeared. No lens opacities developed and on discharge on June 9, the fundus could be seen well and the visual acuity with a pinhole was $6 / 12$, with considerable astigmatism. On June 20 , the eye was quiet and the lens was clear. Visual acuity after refraction was $6 / 9$ with $-1 \mathrm{D}$ sph., $+3 \mathrm{D}$ cyl. at $90^{\circ}$.

My thanks are due to Mr. P. Jameson Evans for his co-operation and assistance with the operation, and to Mr. C. Rudd and Mr. M. Smith, whose case the patient was.

\section{REFERENCES}

Weber, E. (1949). Ophthalmologica (Basel), 117, 238. 